\title{
AGGREGATING FUZZY BINARY RELATIONS AND FUZZY FILTERS
}

\author{
Abdelaziz Amroune And Bouad Aissa \\ Laboratory of Pure and Applied Mathematics \\ Department of Mathematics \\ Mohamed Boudiaf University \\ Msila 28000, Algeria \\ e-mail: aamrounedz@yahoo.fr \\ aissa.bouad@yahoo.com
}

\begin{abstract}
The main goal of this paper is to investigate the aggregation of diverse families of binary fuzzy relations, fuzzy filters, and fuzzy lattices. Some links between these families and their images via an aggregation are explored.
\end{abstract}

Keywords: aggregation, fuzzy relation, fuzzy lattices, fuzzy filter, trace.

2010 Mathematics Subject Classification: 03E72, 06D72, 06B10, 97H50.

\section{REFERENCES}

[1] U. Bodenhofer, Representation and constructions of similarity based fuzzy ordering, Fuzzy Sets and Systems 137 (2003) 113-136. doi:10.1016/S0165-0114(02)00436-0

[2] T. Calvo, Gaspar Mayor, Radko Mesiar, Aggregation Operators (Physica-Verlag Heidelberg, 2002). doi:10.1007/978-3-7908-1787-4

[3] I. Chon, Fuzzy Partial Order Relations and Fuzzy Lattices, Korean J. Math. 17 (2009) 361-374.

[4] B.A. Davey and H.A. Priestley, Introduction to lattices and order (Second Edition, Cambridge University Press, Cambridge, 2002).

[5] B. De Baets and R. Mesiar, T-partitions, Fuzzy Sets and Systems 97 (1998) 211-223. doi:10.1016/S0165-0114(96)00331-4

[6] J.C. Fodor, Traces of fuzzy binary relations, Fuzzy Sets and Systems 50 (1992) 331-341. doi:10.1016/0165-0114(92)90229-W 
[7] U. Höhle and N. Blanchard, Partial ordering in L-underdeterminate sets, Information Sciences 35 (1985) 133-144. doi:10.1016/0165-0114(92)90229-W

[8] E.P. Klement, R. Mesiar and E. Pap, Triangular Norms (Trends in Logic, Vol. 8, Kluwer Academic Publishers, Dordrecht, 2000).

[9] I. Mezzomo, B.C. Bedregal and R.H.N. Santiago, Kinds of ideals of fuzzy lattice, Second Brasilian Congress on Fuzzy Systems (2012) 657-671.

[10] I. Mezzomo, B.C. Bedregal and R.H.N. Santiago, On fuzzy ideals of fuzzy lattice, International Conference on Fuzzy Systems (2012) 1-5.

doi:10.1109/FUZZ-IEEE.2012.6251307

[11] SV. Ovchinnikov, Similarity relations, fuzzy partitions, and fuzzy orderings, Fuzzy Sets and Systems 40 (1991) 107-126. doi:10.1016/0165-0114(91)90048-U

[12] Renata H.S, Reiser, B. Bedregal and M. Baczynski, Aggregating fuzzy implications, Information Sciences 253 (2013) 126-146.

doi:10.1016/j.ins.2013.08.026

[13] L. Valverde, On the structure of F-indistinguishability operators, Fuzzy Sets and Systems 17 (1985) 313-328. doi:10.1016/0165-0114(85)90096-X

[14] L.A. Zadeh, Fuzzy sets, Information and Control 8 (1965) 338-353.

[15] L.A. Zadeh, Similarity relations and fuzzy orderings, Information Sciences 3 (1971) 177-200.

Received 1 January 2018

Revised 10 July 2018

Accepted 17 September 2018 